\title{
ROLE OF FESS IN NASAL POLYPOSIS
}

\author{
Subhash Kumar' ${ }^{1}$ Manjit Singh², Baldev Singh ${ }^{3}$, Anmol Singh ${ }^{4}$ \\ ${ }_{1}^{1}$ Senior Resident, Department of Surgical Oncology, GMC and RH, Patiala, Punjab. \\ ${ }^{2}$ Associate Professor, Department of ENT, GMC and RH, Patiala, Punjab. \\ 4 Professor, Department of ENT, GMC and RH, Patiala, Punjab. \\ ${ }_{3}^{3} M B B S$ Intern, GMCH, Chandigarh, Punjab,
}

ABSTRACT
BACKGROUND
Nasal polyposis is the most common chronic disease affecting the mucous membranes of the nasal cavity and the paranasal
sinuses, and following chronic sinusitis it is the most frequent indication for surgical intervention in the nose and paranasal
sinuses.

\section{MATERIALS AND METHODS}

Functional endoscopic sinus surgery (FESS) is a minimally invasive technique that uses an endoscope to improve ventilation and drainage in addition to polyp removal. This technique has been used for more than a decade in treating sinonasal conditions. Its advantages are claimed over conventional surgery permitting a better view of surgical field, a more precise and thorough clearance of the disease process, fewer complications and lower recurrence rates.

\section{RESULTS}

The results of study revealed that endoscopic sinus surgery for nasal polyposis is a safe and simple procedure. As the procedure is carried out under direct magnified vision, bleeding is minimal and hospital stay of the patient is minimal and hence economical.

\section{CONCLUSION}

This study was conducted in the Department of Otorhinolaryngology, Rajindra Hospital, Patiala, Punjab, India. Forty patients presenting with nasal polyposis were included in the study. They were divided into two groups of 20 patients each. Group A was treated by conventional techniques of surgery and Group B was treated by endoscopic sinus surgery. Observations were made regarding the complications, recurrence of disease and relief from symptoms. The response to the treatment was determined on the basis of subjective improvement of symptoms. The response was categorised. The age of the patient in this study range varied from 9 to 52 years.

\section{KEYWORDS}

FESS, Nasal Polyposis, Nasal Obstruction, Uncinate Process.

HOW TO CITE THIS ARTICLE: Kumar S, Singh M, Singh B, et al. Role of FESS in nasal polyposis. J. Evolution Med. Dent. Sci. 2018;7(13):1592-1595, DOI: 10.14260/jemds/2018/360

\begin{abstract}
BACKGROUND
Functional endoscopic sinus surgery (FESS) is a minimally invasive technique that uses an endoscope to improve ventilation. Its advantages are claimed over conventional surgery permitting a better view of surgical field, a more precise and thorough clearance of the disease process, fewer complications and lower recurrence rates.[1] Diagnostic nasal and sinus endoscopy was first used by Hirschmann in 1903 using a modified cystoscope. Based primarily on the concepts developed by Wigand and Messerklinger, the technique has since been adopted by several workers in this field. [2] The keystone of FESS is its ability to accurately diagnose even relatively minor changes of the frontal and maxillary sinuses. The purpose of the FESS is to re-establish ventilation and mucociliary clearance of sinuses. The technique allows direct magnified visualisation of inside of the nose and paranasal
\end{abstract}

'Financial or Other Competing Interest': None.

Submission 11-02-2018, Peer Review 02-03-2018,

Acceptance 05-03-2018, Published 26-03-2018.

Corresponding Author:

Manjit Singh,

Associate Professor,

Department of ENT,

GMC and RH, Patiala, Punjab.

E-mail: drmanjitsingh62@yahoo.com

DOI: $10.14260 /$ jemds $/ 2018 / 360$

(c) (i) $(9)$ sinuses (PNS) with minimal morbidity and bleeding. [3] Nasal polyposis is the most common chronic disease affecting the mucous membranes of the nasal cavity and the PNS, and following chronic sinusitis it is the most frequent indication for surgical intervention in the nose and PNS. Nasal polyposis is not a single disease entity. There are at least two and probably more clinically and pathophysiologically distinct manifestations.[4] Polyp development has been linked to chronic inflammation, allergy and genetic predisposition. The aetiology of the nasal polyp is unknown. Some theories consider polyps a consequence of conditions that cause chronic inflammation in the nose and nasal sinuses characterised by stromal oedema and variable cellular infiltrate.[5] There is some evidence for involvement of a genetic element to nasal polyps. A link has been shown recently between HLA-A 74 and nasal polyps.[6]

\section{Aims and Objectives}

- To study the clinical effectiveness and role of functional endoscopic sinus surgery for removal of nasal polyps.

- To analyse and diagnose the postoperative benefits of the endoscopic sinus surgery over various other surgical methods. 


\section{MATERIALS AND METHODS}

This is a non-randomised controlled trial conducted in the Department of Otorhinolaryngology, Rajindra Hospital, Patiala, Punjab, India. Forty patients presenting with nasal polyposis were included in it. The sample size was determined on the basis of the turnover of patients in the outdoor patient department of ENT Department of GMC and $\mathrm{RH}$, Patiala during the period of study. In addition, there is limitation. It should have enrolled more than 40 patients with polyps.

The allocation of patients has been done into two groups of twenty patients each. After primary inclusion, all patients were taken up for diagnostic endoscopic sinus endoscopy with both $0^{\circ}$ and $30^{\circ}$ endoscopes for further exclusion.

\section{Also, the Understated were further Excluded from the Study-}

1. Disease inaccessible by endoscopic procedures.

2. Patients with osteomyelitis.

3. Threatened intracranial or intraorbital complications.

Furthermore, an equitable distribution across both groups (Group $A=$ conventional surgery, Group $B=$ endoscopic sinus surgery) was attempted on the basis of CT scan findings and multiple instances of preoperative diagnostic nasal endoscopy.

Group A was treated by conventional techniques of surgery and Group B was treated by endoscopic sinus surgery. Computerised tomography (CT) scan of the PNS (both coronal and axial) with contrast was conducted in patients of both the groups. Coronal cuts of $5 \mathrm{~mm}$ with $3 \mathrm{~mm}$ cuts in the osteomeatal unit were taken in these cases. All the patients who were included in Group B were then subjected to diagnostic endoscopic examination of the nose under local anaesthesia. A 4-mm 30-degree telescope was passed three times for the examination of nasal cavity. Patients belonging to Group B were treated by endoscopic sinus surgery and those belonging to Group A were treated by conventional techniques that included Caldwell-Luc operation, and intranasal ethmoidectomy and an additional procedure (septoplasty). The instruments used for endoscopic sinus surgery included a Hopkins rod optic telescope with deflections of view $0^{\circ}, 30^{\circ}$ and $70^{\circ}$. The sizes of the telescopes were 4 and $2.7 \mathrm{~mm}$. An infundibulotomy (uncinectomy) was then performed with a sickle knife. The polyps were then removed. Patients were closely followed up initially at 2-day, weekly and bi-weekly intervals and then at monthly interval for 6 months. Observations were made regarding the complications, recurrence of disease and relief from symptoms. The response to the treatment was made on the basis of subjective improvement of symptoms.

\section{The Response was categorised as under-}

- Complete response: when the patient had 90\% - 100\% relief.

- $\quad$ Partial response: when the patient had 50\% - 90\% relief.

- No response: when the patient had below $50 \%$ relief.

\section{Statistical Analysis}

The "Pearson chi-square" test was used for analysis and the ' $p$ ' value had been analysed (which was found to be significant at a value of $<0.05$ as shown in the table attached below. This analysis was performed with IBM SPSS 22 version.

\section{RESULTS}

In this study, the age of the patient range varied from 9 to 52 years. The maximum number of patients were in the age group of $20-29$ years (30\%). The male/ female ratio was 1.8:1. There was a male predominance in all the age groups. All the 40 patients complained of nasal obstruction. Other complaints were nasal discharge (20), headache (09), nasal bleeding (02), anosmia (08) and PND (12). All patients were subjected to anterior rhinoscopy. It was found that 40 patients had polyps. Excessive nasal discharge was found in 34 patients; middle turbinate view was obscured in 9 patients; septum was deviated in 12 patients; and inferior turbinate hypertrophy was observed in 18 patients. A diagnostic endoscopic examination was carried out in all patients belonging to Group B (Fig. 1). Polyps were confirmed with 6 having unilateral and 14 having bilateral polyps, paradoxical middle turbinate in 3, DNS in 5, mucopus in 8 and concha bullosa in 1 patient. CT was performed in all patients belonging to both groups (Fig. 2). Intracranial extension was not observed in any of the patients. One patient of Group B also showed sphenoidal involvement. In Group A, there were 11 patients who had antrochonal polyps and 9 patients who had ethmoidal polyps. In Group B, 6 patients had antrochoanal polyps, 8 had ethmoidal polyps and 12 had middle meatal polyps.

\begin{tabular}{|c|c|}
\hline Procedure & No. of Cases \\
\hline Caldwell-Luc & 7 \\
\hline Intranasal Ethmoidectomy & 6 \\
\hline Caldwell-Luc + Septoplasty & 4 \\
\hline Ethmoidectomy + Septoplasty & 3 \\
\hline \multicolumn{2}{|c|}{ Surgical Procedures in Group A (Fig. 3) } \\
\hline
\end{tabular}

\begin{tabular}{|c|c|}
\hline Procedure & No. of Cases \\
\hline Polypectomy & 6 \\
\hline Polypectomy + Uncinectomy & 3 \\
\hline $\begin{array}{c}\text { Polypectomy + Uncinectomy + Bullectomy + } \\
\text { Ethmoidectomy }\end{array}$ & 1 \\
\hline Polypectomy + Uncinectomy + Ethmoidectomy & 2 \\
\hline Polypectomy + Uncinectomy + Septoplasty & 2 \\
\hline Polypectomy + Septoplasty & 2 \\
\hline $\begin{array}{c}\text { Uncinectomy + Bullectomy + Ethmoidectomy + } \\
\text { Sphenoidotomy }\end{array}$ & 1 \\
\hline Polypectomy + Ethmoidectomy + Septoplasty & 1 \\
\hline Uncinectomy + Ethmoidectomy & 1 \\
\hline Uncinectomy + MMA & 1 \\
\hline \multicolumn{2}{|l|}{ Surgical Procedures in Group B (Fig. 4) } \\
\hline
\end{tabular}

No major complications occurred in our study. One patient belonging to Group B had wound infection. There were two cases of external haematoma in each group. One case of lamina papyracea injury in Group B and two in patients from Group A were seen. Two cases of bleeding pack were observed in Group B and 9 in Group A. The follow-up period varied from 4 to 6 months. They were observed for any complication, recovery, recurrence and synechiae formation. By the sixth month it was observed that in Group A 11 patients had recovery, 2 had synechiae formation and 7 had recurrence of the disease process. In Group B by the sixth 
month 16 had recovery, 3 had synechiae formation and 1 had recurrence. Final result are given in the table below:

\begin{tabular}{|c|c|c|}
\hline Final Result & Group A & Group B \\
\hline Complete relief & 6 & 16 \\
\hline Partial relief & 8 & 4 \\
\hline No relief & 6 & 0 \\
\hline
\end{tabular}

Chi-square tests.

\begin{tabular}{|l|c|c|c|}
\hline & Value & df & $\begin{array}{c}\text { Asymp. Sig. } \\
\text { (Two-Sided) }\end{array}$ \\
\hline Pearson's Chi-square & $11.879(\mathrm{a})$ & 2 & $0.003^{* *}$ \\
\hline
\end{tabular}

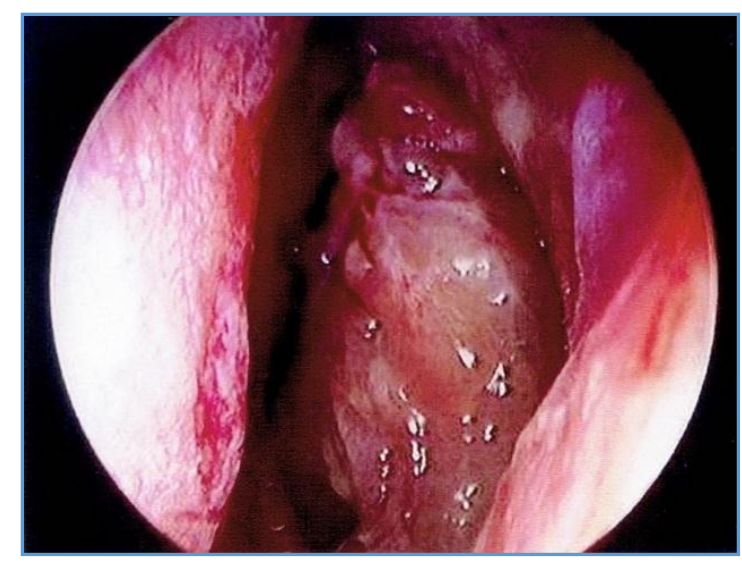

Figure 1. Polyp in Middle Meatus: Endoscopic View

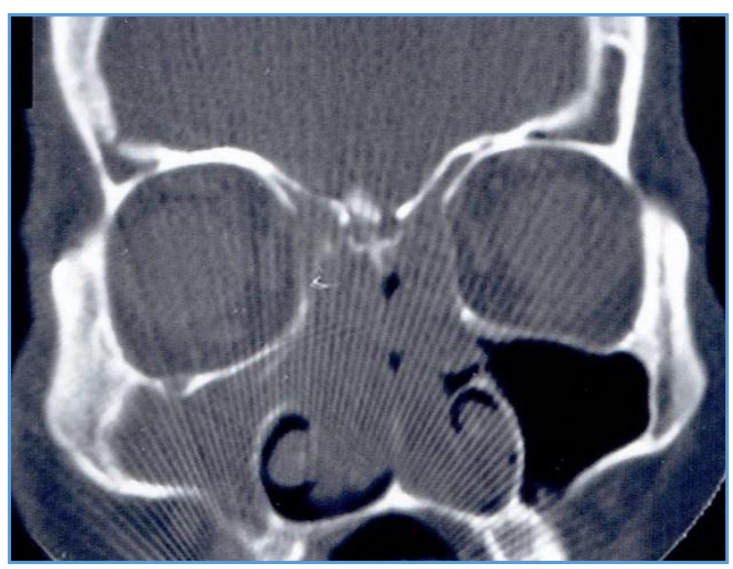

Figure 2. Nasal Cavity and Paranasal Sinuses CT Scan showing the Bilateral Involvement of Nasal Cavities, Ethmoidal Sinuses and Right Maxillary Sinus

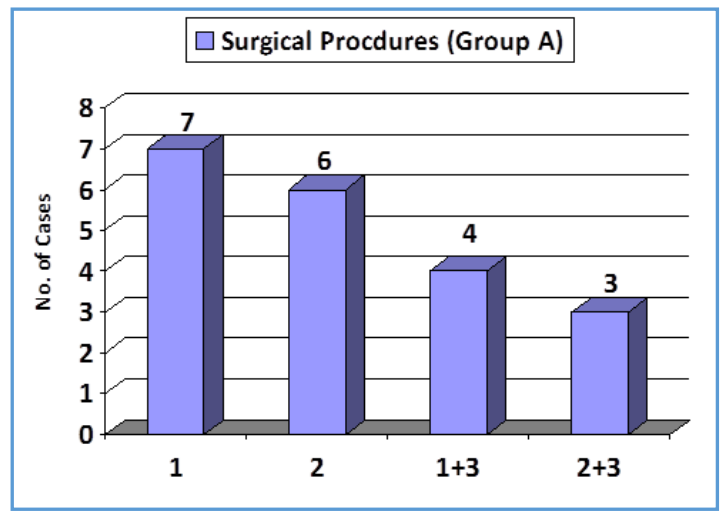

Figure 3. Procedures: (1) Caldwell-Luc, (2) Intranasal Ethmoidectomy and (3) Septoplasty

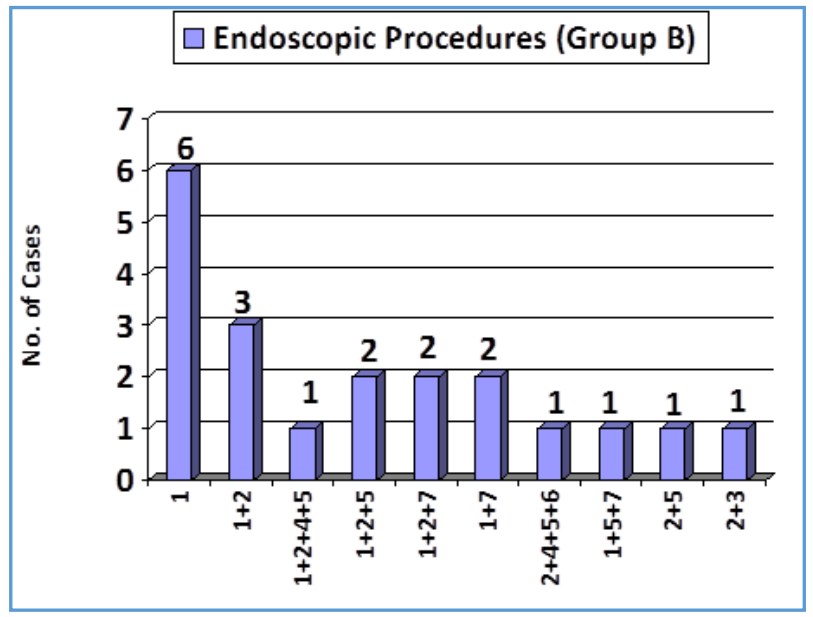

Figure 4. Procedures: (1) Caldwell-Luc,

(2) Uncinectomy, (3) MMA, (4) Bullectomy,

(5) Ethmoidectomy, (6) Sphenoidotomy and (7) Septoplasty

\section{DISCUSSION}

Nasal polyposis is a challenge to the treating clinician. The aetiology of polyposis is still unclear, yet various factors such as those contributing to the development of nasal polyps have been implicated. The surgical approach for nasal polyps dates back to the time of Hippocrates. Since then, various modifications have been made in the surgical techniques. For the management, various options are available. Still it is tricky due to the failure to remove the disease in total from the narrow clefts between the middle turbinate and the internal wall of the nose.[7] A total of 40 patients with nasal polyposis constituted this study. They were divided into two groups of 20 patients. Group A was treated by conventional methods of surgery without using an endoscope. Group B was treated by endoscopic sinus surgery by using an endoscope. The age of the patients varied from 9 to 52 years with majority of them in the age group of $10-29$ years. The male/female ratio was 1.8:1. These findings are similar to those of Frankie,[8] Drake-Lee,[9] Rice,[7] Venkatachalam[10] and Dalziel et al.[1] The high incidence of nasal polyps in the second and third decades of life explains the aetiology of nasal polyposis, that is infection and vasomotor imbalance.[11] This age group is more vulnerable to infection, anxiety, conflicts and tensions of day-to-day life. Also, they are exposed to a variety of pollutants that lead to infection and allergic conditions of the mucosa of nose and paranasal sinus. This in turn predisposes to the polyp formation. These findings are similar to those of Frankie, ${ }^{[8]}$ Drake-Lee, ${ }^{[9]}$ Rice, ${ }^{[7]}$ Venkatachalam,[10] Dalziel et al[1] and Gulati et al.[12] This is probably because males are more mobile compared to females, due to which they are more exposed to day-to-day pollutants. Also, they are also more prone to vasomotor imbalance. Nasal polyposis can present with a variety of symptoms, the most common being nasal obstruction. The other symptoms are nasal discharge, headache, anosmia and nasal bleeding. $[1,8,10,13]$ The duration of symptoms varied from 6 to 36 months. The mean duration was 18.475 months. Rice, [7] in his series of 100 patients, found the duration of complaints varying from 6 months to 25 years. This explains the various initial changes that take place. These are blockage, stasis, infection and further blockage before the formation of full-blown polyp. The duration of symptoms 
observed by Venkatachalam[10] was 6 - 36 months. Dalziel et al[1] observed in their study that the duration of symptoms was 6 - 14 months. 16 patients from Group B (80\%) had complete relief from symptoms after 6 months, whereas only 6 patients $(30 \%)$ from Group A had complete relief. Four patients (20\%) from Group B and eight patients (40\%) from Group A had partial relief from symptoms. Six patients from Group A (30\%) had no relief from symptoms after 6 months of follow-up. Rice,[7] in his series of 100 patients who underwent endoscopic sinus surgery reported complete relief of symptoms in $83 \%$ of the patients, partial relief of symptoms in $10 \%$ of cases and no response in $7 \%$ patients. Schaefer et $\mathrm{al}^{,[14]}$ in their series of 100 patients who underwent the same surgery reported therapeutic improvement in 83 patients. Adil et al[15] observed a success rate of $80.7 \%$ in FESS for treatment of nasal polyposis. Venkatachalam[10] studied 15 patients and reported a success rate of $73.3 \%$. Dalziel et al[1] reported that symptomatic improvement ranged from $78 \%$ to $88 \%$ of FESS compared with $43 \%$ - $84 \%$ for comparative procedure. Chopra[16] observed a success rate of $82 \%$ and patients had achieved improvement in preoperative symptoms. Gulati et al[12] reported a success rate of $90 \%$ and only $10 \%$ patients needed revision surgery. Alam et al[13] observed that controlled symptomatic improvement ranged from $78 \%$ to $88 \%$ for FESS compared with $43 \%$ - $84 \%$ for conventional techniques. We would like to point out that the discrepancy in the percentage of success rate is due to different modes of evaluation, extent of the disease and presence of allergic element in these cases. FESS may offer some advantages in effectiveness over comparative techniques, but there is enormous variation in the results reported and there are methodological limitations. There is a clear need for qualitycontrolled trials to answer questions regarding the effectiveness of the FESS. This study has revealed that in the management of nasal polyp the results with endoscopic sinus surgery are better than those obtained with the traditional surgery in terms of both from the relief of symptom and incidence of complications.

\section{Limitations}

Since the calculated sample size was too less and thereby not feasible to include in this limited period of study, we had to limit the sample size for convenience.

\section{CONCLUSION}

This study revealed that endoscopic sinus surgery for nasal polyposis is a safe and simple procedure. It can be easily carried out under local anaesthesia, thereby avoiding the complications associated with general anaesthesia. The deflected views as well as better views of illumination of the telescopes enable the surgeon to completely remove the disease from the nasal cavity. As the procedure is carried out under direct magnified vision, bleeding is minimal and consequently there is no need of postoperative anterior nasal pack. Hospital stay of the patient is minimal and hence economical; photographic documentation facilitates a meaningful postoperative follow-up of these patients. CT and nasal endoscopy are complimentary to each other in the diagnosis and management of nasal polyps. Endoscopic sinus surgery enables the surgeon to accurately diagnose nasal polyp, precisely and atraumatically clear the disease from the narrow cleft between the middle meatus and the lateral wall, and quickly provide meticulous postoperative care. Because the uninvolved structures remain untouched, this focal management minimises morbidity. It is felt that the diagnosis and postoperative utility of the endoscope will benefit all the patients of nasal polyposis irrespective of the surgical technique involved.

\section{REFERENCES}

[1] Dalziel K, Stein K, Round A, et al. Systematic review of endoscopic sinus surgery for nasal polyps. Health Technol Assess 2003;7(17):1-159.

[2] Kaluskar SK, Patil NP. Functional endoscopic sinus surgery: philosophy and current concepts. Indian J Otolaryngol Head Neck Surg 1992;3:108-12.

[3] Kennedy DW. Functional endoscopic sinus surgery. Technique. Arch Otolaryngol 1985;111(10):643-9.

[4] Stammberger H, Hawke M. Essentials of functional endoscopic sinus surgery. St. Louis: Mosby, 1993:1342.

[5] Bateman ND, Fahy C, Woolford TJ. Nasal polyps: still more questions than answers. J Laryngol Otol 2003;117(1):1-9.

[6] Luxenburger $W$, Posch U, Berghold A, et al. HLA patterns in patients with nasal polyposis. Eur Arch Otorhinolaryngol 2000;257(3):137-9.

[7] Rice DH. Endoscopic sinus surgery: results at 2 years follow-up. Otolaryngol Head Neck Surg 1989;101(4):476-9.

[8] Frenkiel S, Small P, Rochon L, et al. Nasal polyposis, a multidisciplinary study. J Otolaryngol 1982;11(4):2758.

[9] Drake-Lee AB, Lowe D, Swatson A, et al. Clinical profile and recurrence of nasal polyps. J Larynol Otol 1984;98(8):783-93.

[10] Venkatachalam VP, Bhat A. Comparative evaluation of endoscopic \& conventional surgical techniques in the management of nasal polyposis. JK Pract 1998;5(4):295-9.

[11] Drake-Lee AB. In: Scott Brown's diseases of the ear, nose and throat. $5^{\text {th }}$ edn. London: Butterworths, 1987:pp 142.

[12] Gulati S, Anshu, Wadhera R, et al. Efficacy of functional endoscopic sinus surgery in the treatment of ethmoidal polyps. Internet J Otorhinolaryngology 2007;7(1).

[13] Alam M, Fakir AY, Chowdhury A. A review of nasal polyposis and surgical management. Bangladesh J Otolaryngol 2008;14(2):71-4.

[14] Schaefer SD, Manning S, Close LG. Endoscopic paranasal sinus surgery: indications and considerations. Laryngoscope 1989;99(1):1-5.

[15] Adil E, Cavit O, Unal B, et al. Functional endoscopic sinus surgery. Turk J Med Res 1993;11:221-3.

[16] Chopra H, Khurana AS, Munjal M, et al. Role of FESS in chronic sinusitis. Indian J Otolaryngol Head Neck Surg 2006;58(2):137-40. 